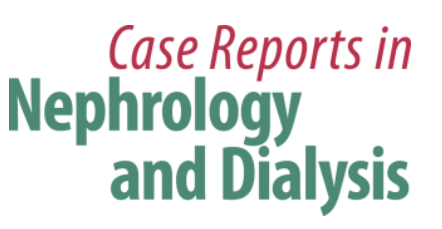

Case Rep Nephrol Dial 2019;9:79-84

DOI: 10.1159/000500948

Published online: June 6, 2019

(c) 2019 The Author(s)

Published by S. Karger AG, Basel

www.karger.com/cnd

This article is licensed under the Creative Commons Attribution-NonCommercial 4.0 International License (CC BY-NC) (http://www.karger.com/Services/OpenAccessLicense). Usage and distribution for commercial purposes requires written permission.

\title{
Remission of Membranous Nephropathy after Treatment of Localised Prostate Cancer
}

\author{
Daniel Adlington Jason Moore Coralie Bingham
}

Royal Devon and Exeter Hospital, Exeter, UK

\section{Keywords}

Prostate cancer $\cdot$ Membranous nephropathy $\cdot$ Androgen deprivation

\begin{abstract}
Membranous nephropathy is a cause of the nephrotic syndrome in adults; it can be a primary or secondary process. Secondary causes include solid organ and lymphoid malignancies. Prostate cancer has been reported as the second most common causative malignancy. Remission of membranous nephropathy following treatment of metastatic prostate cancer is well established. In this case, we describe a patient with localised prostate cancer who developed severe nephrotic syndrome (urine protein creatinine ratio $1,616 \mathrm{mg} / \mathrm{mmol}$ and serum albumin $17 \mathrm{~g} / \mathrm{L}$ ) secondary to membranous nephropathy. The prostate cancer was deemed of low risk and so was being managed with active surveillance rather than medical treatment. Given the severity of the nephrotic syndrome a trial of androgen deprivation therapy with bicalutamide was agreed between the nephrology and urology teams. Full remission of the nephrotic syndrome was observed within 6 months of commencement of treatment (normalisation of serum albumin, non-nephrotic range urine protein creatinine ratio and resolution of oedema). The bicalutamide has been continued indefinitely.




\section{Case Reports in Nephrology and Dialysis}

\section{Introduction}

Membranous nephropathy is a pathological disease characterised by fine, granular, immune deposits of IgG and complement components in the subepithelial space with thickening of the glomerular basement membrane. Glomerular basement membrane extending round subepithelial deposits may be seen as "spikes" on silver stains under light microscopy; subepithelial electron-dense deposits are seen on electron microscopy. Membranous nephropathy is the most common cause of nephrotic syndrome in adults accounting for around $20 \%$ of cases [1]. The disease can occur as a primary or secondary process, with secondary causes including malignancies, infections, autoimmune disease and drug toxicities [2]. We report the first case of remission of membranous nephropathy in a patient with localised prostate cancer who would not otherwise have received medical treatment.

\section{Case Report}

A 75-year-old man was referred to the nephrology clinic with a 3-month history of progressive oedema involving his legs, abdomen and scrotum associated with orthopnoea and fatigue. He had mild, long-standing, lower urinary tract symptoms relating to known prostatic enlargement. He had been commenced on oral frusemide which had stabilised his fluid retention.

His past medical history included localised adenocarcinoma of the prostate, $<5 \%$ Gleason $3+4$ disease on the right side of the gland and $1 \%$ Gleason $3+3$ disease on the left diagnosed on prostate biopsy 1 year previously. This followed surveillance for a raised prostate-specific antigen (PSA) and identification of two suspicious lesions on MRI scan (PI-RADS 4/5) on the left side of the gland. He also had a history of ischaemic heart disease, coeliac disease (diagnosed 6 years prior and now stable and asymptomatic on a gluten-free diet), diverticulosis, colonic polyps with low-grade dysplasia and skin lesions in the form of two previous basal cell carcinomas and melanoma in situ which had all been fully excised. He was not taking any nephrotoxic medications. There was no family history of renal disease. He had never smoked.

On examination, he was normotensive (blood pressure 142/82) with an elevated jugular venous pressure and a clear chest to auscultation. He had peripheral oedema to mid abdomen and his weight, at $105 \mathrm{~kg}$, was estimated to be $20 \mathrm{~kg}$ above his normal body weight.

Initial investigations showed a urine dipstick positive for protein $3+$ and blood $3+$. He had nephrotic range proteinuria with a urine protein creatinine ratio (UPCR) elevated at 722.5 $\mathrm{mg} / \mathrm{mmol}$. His serum albumin was low at $21 \mathrm{~g} / \mathrm{L}$ with renal function within the normal range, creatinine $62 \mu \mathrm{mol} / \mathrm{L}$, urea $5.9 \mathrm{mmol} / \mathrm{L}$, eGFR $>90 \mathrm{~mL} / \mathrm{min}$; his cholesterol was $6.9 \mathrm{mmol} / \mathrm{L}$. His current PSA was $6.13 \mu \mathrm{g} / \mathrm{L}$ (reference range $0-5$ ), which had remained stable over the past 2 years. A renal immunological screen including anti-nuclear antibody, anti-neutrophil cytoplasmic antibody titre and anti-glomerular basement membrane was negative. His complement levels were normal. An ultrasound scan of the renal tract revealed normal renal size and morphology and no other abnormalities. His chest X-ray showed small bilateral pleural effusions, the lungs were otherwise clear, his heart size and mediastinal contour were normal.

A clinical diagnosis of nephrotic syndrome was made, and he underwent a renal biopsy to obtain a histological diagnosis. Membranous nephropathy was confirmed on biopsy. Light microscopy showed 13 glomeruli, none of which were globally sclerosed. The glomeruli were normocellular with patent capillary loops. There was subtle capillary wall thickening, but no spikes or double contouring were seen on silver stain. There was no interstitial inflammation, 


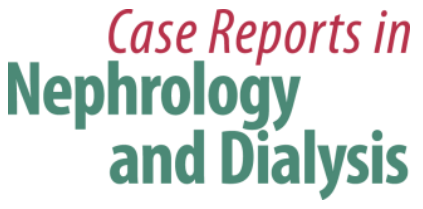

Case Rep Nephrol Dial 2019;9:79-84

DOI: $10.1159 / 000500948$

(c) 2019 The Author(s). Published by S. Karger AG, Basel www.karger.com/cnd

Adlington et al.: Remission of Membranous Nephropathy after Treatment of Localised Prostate Cancer

oedema or scarring. Immunofluorescence was strongly positive for immunoglobulin G deposited in a granular pattern. On electron microscopy, there were abundant subepithelial immune deposits with basement membrane spike formation and extensive epithelial foot process effacement.

He was negative for serum anti-phospholipase A2 antibody (anti-PLA2R), which raised the possibility of a secondary membranous nephropathy. Testing for anti-thrombospondin type 1 (anti-THSD7A) was also negative. Viral serology for hepatitis B, C and HIV were all negative. Given his history of skin cancers he had a skin examination by a dermatologist that did not reveal any suspicious lesions. Initial treatment was a watch-and-wait approach with diuretics, angiotensin-converting enzyme inhibition and a statin.

Despite this, his uPCR continued to rise to $1,325 \mathrm{mg} / \mathrm{mmol}$ in combination with a fall in his albumin to $17 \mathrm{~g} / \mathrm{L}$. Given his falling albumin, he was commenced on warfarin anti-coagulation. His underlying low-grade prostate malignancy seemed a possible cause for his severe membranous nephropathy and so a further opinion was sought from the urologists.

His prostate cancer was thought to be of low to intermediate risk and he was being managed with active surveillance through serial PSA readings, which were remaining stable at $6.13 \mu \mathrm{g} / \mathrm{L}$ when he was diagnosed with nephrotic syndrome. There was no pelvic lymphadenopathy on the MRI scan of his prostate at the time of his prostate biopsy. An up-to-date CT scan of his abdomen and pelvis showed pleural fluid, ascites and oedema in keeping with nephrotic syndrome but no obvious primary tumour or metastases. There were bilateral pelvic lymph nodes measuring up to $13 \mathrm{~mm}$ in diameter. Given his very stable and indolent disease, the urologists were initially unconvinced that the prostate cancer could be associated with the membranous nephropathy. However, after further discussion in a urology cancer multi-disciplinary team meeting with attendance and discussion by the nephrologists, it was agreed that a trial of androgen deprivation therapy with bicalutamide would be carried out.

One month after the commencement of treatment with bicalutamide, there was an improvement in his peripheral oedema in combination with a rise in serum albumin $(23 \mathrm{~g} / \mathrm{L})$ and fall in uPCR ( $830 \mathrm{mg} / \mathrm{mmol}$ from a peak of $1,616 \mathrm{mg} / \mathrm{mmol})$. Warfarin was stopped at this point. The trend continued over the following months and 6 months following treatment he was deemed in full remission with complete resolution of oedema, and normalisation of serum albumin to $35 \mathrm{~g} / \mathrm{L}$ and uPCR now non-nephrotic range at $337 \mathrm{mg} / \mathrm{mmol}$ (Fig. 1). As a result, in view of his rapid response, a decision to continue the bicalutamide indefinitely, so long as it was well tolerated, was agreed at the subsequent multi-disciplinary team meeting. Proteinuria continued to normalise and most recently, at 12 months, uPCR was $66 \mathrm{mg} / \mathrm{mmol}$. A repeat MRI scan of the pelvis showed no lymphadenopathy.

\section{Discussion/Conclusion}

Membranous nephropathy can be a primary or secondary process with secondary membranous nephropathy accounting for $20 \%$ cases. The IgG4 autoantibody to the podocyte membrane antigen PLA2R has been strongly associated with primary membranous disease [3]. A second IgG4 antibody specific for THSD7A, another podocyte membrane antigen, has been identified in $2-5 \%$ patients. There is a higher frequency of associated malignancies and a female predominance with anti-THSD7A [4]. Our patient was negative for both anti-PLA2R and anti-THSD7A antibodies.

The first report of an association between prostatic malignancy and development of membranous nephropathy was in 1986 [5]. Further literature since then has supported the 


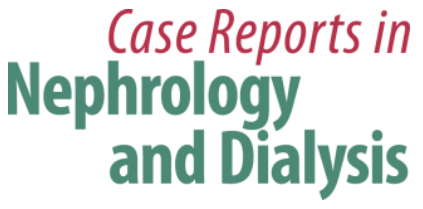

Case Rep Nephrol Dial 2019;9:79-84

DOI: $10.1159 / 000500948$

(c) 2019 The Author(s). Published by S. Karger AG, Basel www.karger.com/cnd

Adlington et al.: Remission of Membranous Nephropathy after Treatment of Localised Prostate Cancer

link between prostatic malignancy and membranous disease [6]. These reports have, however, largely described this association in the context of metastatic prostatic disease rather than the localised cancer described in our case. A recent systematic review and meta-analysis of observational studies investigating the link between malignancy and membranous disease identified prostate malignancy as being the second most common cancer to be associated with membranous disease [2]. This frequency is much higher than previously reported and the authors attribute this to recent studies which reflect increased screening practices for prostate cancer, and therefore a higher diagnosis rate. The paper does not, however, describe how the cases were treated or the long-term outcomes of these patients.

Current NICE guidelines for the management of prostate cancer are based on the perceived risk as defined by a combination of PSA, Gleason score and clinical stage [7]. Patients with a low risk, as in our case, should be offered an active surveillance approach with consideration of radical prostatectomy at a later stage if there is localised disease progression. Current guidelines do not advise on the management of para-neoplastic associations and impact on treatment.

The management of a membranous nephropathy occurring in the context of a disseminated prostate cancer involves treating the underlying malignancy and assessing response. There is, however, limited evidence to support the best treatment methods when membranous nephropathy is associated with low-grade or indolent malignancies. We think that this case is interesting because it describes, for the first time, the complete remission of nephrotic syndrome, through hormonal treatment, for a localised and stable prostate cancer that would not otherwise have required treatment. The urologists were initially reluctant to start hormonal treatment because they were unconvinced that such a stable malignancy was associated with the membranous disease. After a discussion between the nephrologists and urologists, a trial of treatment was agreed upon, and subsequent complete remission of nephrotic syndrome was observed. It is, of course, possible that the membranous disease remitted spontaneously and the temporal association with hormonal treatment was coincidental. Male patients are at increased risk of deterioration in renal function [8]. He had heavy proteinuria for more than 6 months and patients with $>8 \mathrm{~g}$ /day of proteinuria for more than 6-12 months have a $66 \%$ chance of developing renal insufficiency, which makes spontaneous remission in our case less likely [8]. There have been a number of case reports suggesting a possible association between membranous nephropathy and coeliac disease [9]. These reports all report the simultaneous onset of the two conditions. In our case, the coeliac disease was diagnosed 6 years prior to the membranous nephropathy and remained stable on a gluten-free diet. As a result, we do not think that this association was relevant to our case. Androgen deprivation therapy has recently been reported in an Asian population with prostate cancer to decrease the risk of a number of autoimmune diseases but not primary membranous glomerulonephritis [10]. There are no other reports of androgen deprivation therapy acting directly on membranous nephropathy.

In conclusion, this case highlights the importance of considering active treatment of lowgrade localised prostate cancer if an association with membranous disease is suspected and the importance of nephrologists acting as advocates for our patients with other clinical teams.

\section{Statement of Ethics}

The authors have no ethical conflicts to disclose. The patient gave consent for the details of his case to be published. 


\section{Case Reports in Nephrology and Dialysis}

\section{Disclosure Statement}

The authors have no conflicts of interest to declare.

\section{Author Contributions}

All authors contributed equally to the text of the manuscript and the literature review. J.M. was responsible for the original diagnosis and treatment.

\section{References}

1 Ponticelli C, Glassock RJ. Glomerular diseases: membranous nephropathy-a modern view. Clin J Am Soc Nephrol. 2014 Mar;9(3):609-16.

2 Leeaphorn N, Kue-A-Pai P, Thamcharoen N, Ungprasert P, Stokes MB, Knight EL. Prevalence of cancer in membranous nephropathy: a systematic review and meta-analysis of observational studies. Am J Nephrol. 2014;40(1):29-35.

3 Beck LH Jr, Bonegio RG, Lambeau G, Beck DM, Powell DW, Cummins TD, et al. M-type phospholipase A2 receptor as target antigen in idiopathic membranous nephropathy. N Engl J Med. 2009 Jul;361(1):11-21.

4 Couser WG. Primary Membranous Nephropathy. Clin J Am Soc Nephrol. 2017 Jun;12 (6):983-97.

5 Stuart K, Fallon BG, Cardi MA. Development of the nephrotic syndrome in a patient with prostatic carcinoma. Am J Med. 1986 Feb;80(2):295-8.

6 Matsuura H, Sakurai M, Arima K. Nephrotic syndrome due to membranous nephropathy associated with metastatic prostate cancer: rapid remission after initial endocrine therapy. Nephron. 2000 Jan;84(1):75-8.

7 NICE. Prostate cancer: diagnosis and management. Clinical Guideline CG175. 2014. Available from: https://www.nice.org.uk/.

8 Reichert LJ, Koene RA, Wetzels JF. Prognostic factors in idiopathic membranous nephropathy. Am J Kidney Dis. 1998 Jan;31(1):1-11.

9 Boonpheng B, Cheungpasitporn W, Wijarnpreecha K. Renal disease in patients with celiac disease. Minerva Med. 2018 Apr;109(2):126-40.

10 Liu JM, Yu CP, Chuang HC, Wu CT, Hsu RJ. Androgen deprivation therapy for prostate cancer and the risk of autoimmune diseases. Prostate Cancer Prostatic Dis. 2019 Jan. DOI: 10.1038/s41391-019-0130-9. 


\section{Case Reports in Nephrology and Dialysis}

Case Rep Nephrol Dial 2019;9:79-84

DOI: 10.1159/000500948 www.karger.com/cnd
whe

Adlington et al.: Remission of Membranous Nephropathy after Treatment of Localised Prostate Cancer

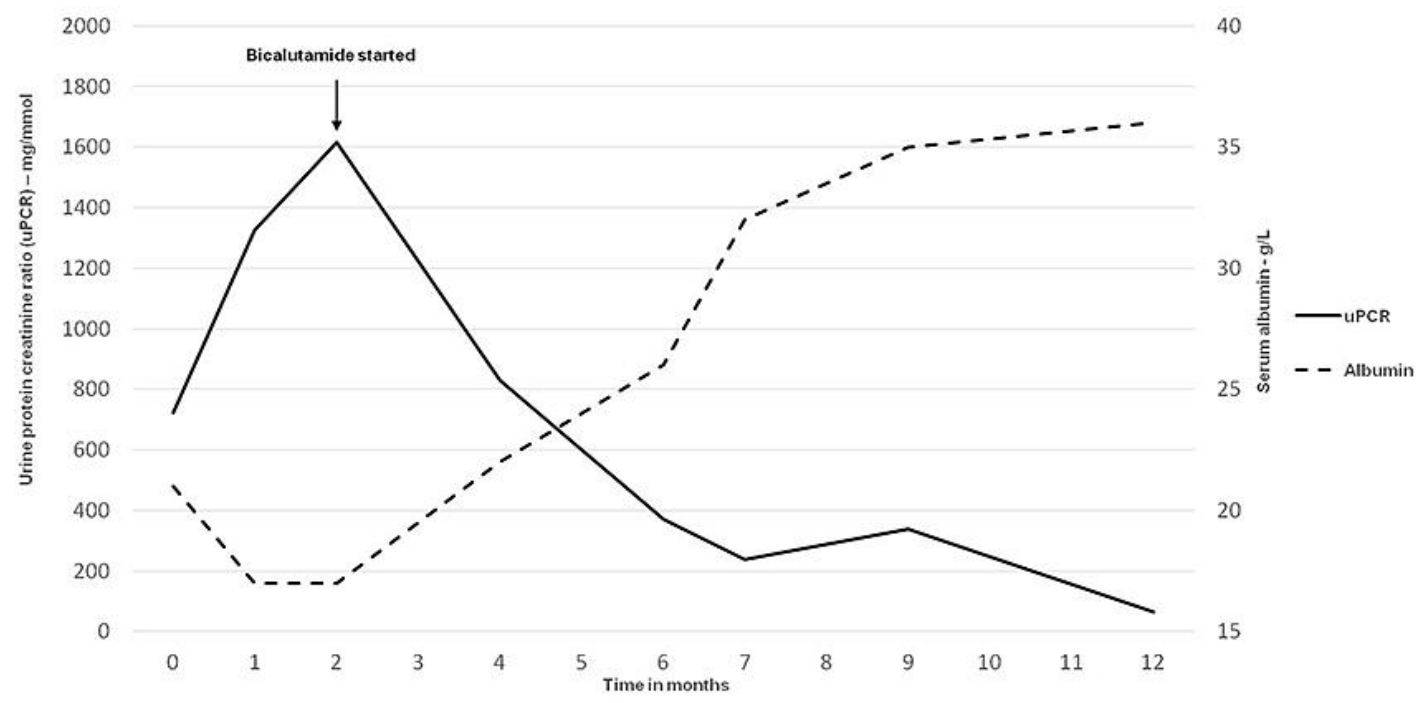

Fig. 1. Urine protein creatinine ratio and serum albumin levels over time before and after the introduction of bicalutamide therapy. 